LA-UR-82-566

$L A-U R--82-566$

DE82 011972

TITLF. ULTRAVIOLET PHASE CONJUGATION

AUTHOR(S) M. M. tkYne, AP-5

Irving J. Biglo, AP-5

Robert $A$. Fisher, AP-5

M. L. Maloney, AP-5

J. R. Busse, AP- 5

R. G. Tercovich, AP-5

B. J. Feldman, AP-5

SUBMITTED TO

International Conference on Lasers 181

New Orleans, Loufstana, Dec, 14-18, 1981

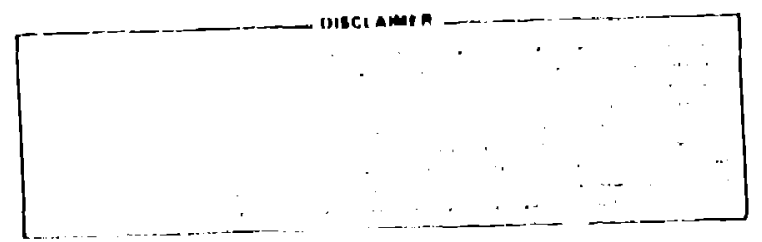

POATIOASS OF THIS REPIIAT ARE ILLERIRLE.

It his beoul repreducoul irom ire boe? avallublo

copy bo pernit use broudeal posablo ovellabilly.

arr uning 


\section{ultraviolet phase conjugation}

M. Slatkine, Irving J. Biglo, Robert A. Fisher. M. L. Maloney, J. R. Busse. R. G. Tércovicn añ B. J. Feidman University of Callforni:

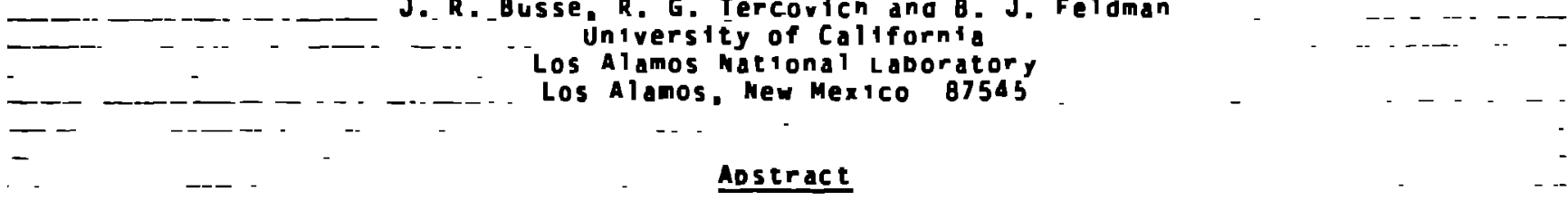

Diffraction-limited onase conjugate reflection of an injection-locked nign-porer (2 $1 \mathrm{MW}$ ) ultraviolet excimer aser deam nas been oemonstrated va stimulated Brilloul. scatteririg. Reflectivities nigher than 702 mere attained. Limftations as -ell as coherence and domer reguirements for image retention are discussej.

\section{Introouction}

Considerable attention has beer giver recently to phase-conjugate reflection [1] of ultraviolec laser deams [2]. Potential adolications, among otners, are in laser fusion and in nign resoluticn photolithograpny [3]. Phase conjugation in tne ultraviolet as first reported using a quaruplea ma:YAG ( 1 - 2660 A) laser [2]. Reflectivities below 0.18 -ere oocainea by oegenerate four-ade mixing in several liquias. Since excimer lasers are the most dowerful ultraviolet radiation sources avalladie coday, mucn effort nas been made to reverse their mavefront. The successful aevelopment of simple injection-lncking techniaues In conjunction - ith these fast ( 20 ns l Dulsed laser suarces has daven the may to the succ-ssful wavefront reversal of pxcimer laser beams. Two approaches have been (andare stili veing) investigated: (a) gegeneratefour-abe mi-irg. Darticularly via the production of inermal gratings [6,7]; (0) wavefront reversal via stimulated Briliouin Dackeara scatering iJBSI.

Altncugn four-maie mialng seems to have some innerent agvantages as to tne ability of reversing nighly aberrated beams, it is not. et clear micn adproach is more oractically efficient ith the nign dower excimer lasers. He nave follomed dotn apdrocnes [7,B]. Ir this paper -e shali empnasize the SBBS apuroach. It is tne purdose of tne present

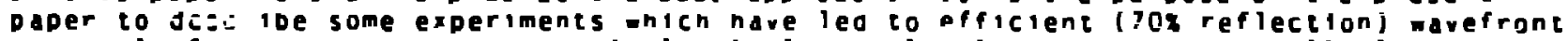

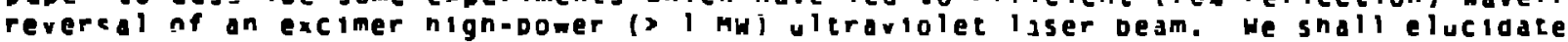
the physical princioles involved with SBBS in terins of diffraction from density gratings. In dnjition. e shall compare the proccss to four-ade mixing.

\section{Degenerate Four-wave Miaing and SPBS}

\section{Degenerate Four-bave mixing}

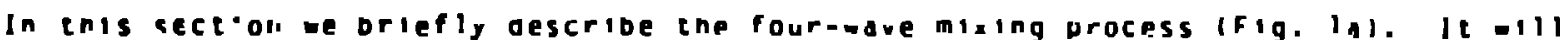
later serve us -o understana SBBS. The experimontal setud consists of two drecisely Counterprudagat.ng dump deams ( $D_{1}$ and $D_{2}$ ) and a probe deam. The drobe beam is usually Guch -eaker than the pump beam and is to br phase conjugatea. Pump di ana the probe besm Interfere to set up an intensity orating enicn generates a material grating through the intaraciun between the ootical field and the material. The secono oump deam ${ }^{2}$ is diffracted (Bragg reflection) from the material grating to adofar as the phase conjugateg probu beam. The raflectivity of eacn Bragg dane deprnas idonn the nonlinear susceptiDility of the acerial and the Dumbs intenstites. There is a typical minimum number of

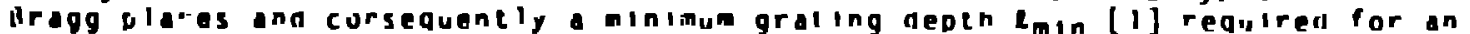
efficient (100r) four-uave mixing pnase conjugato reflection. This minimum length, mhich depenus upon the reflectivity of eacn Braga olanc. determines the crincrence reguirements fron the laser in the real-time nolograbig- exderiment.

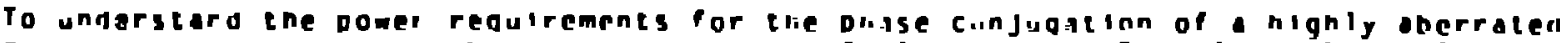

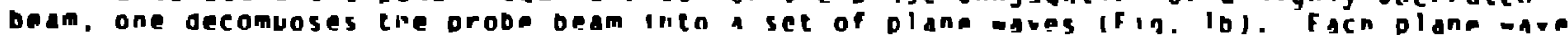

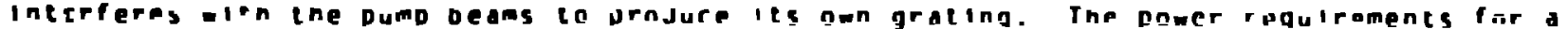
sligle grating roflictlin multiplied by the number of plune ajves intrn depends unon the

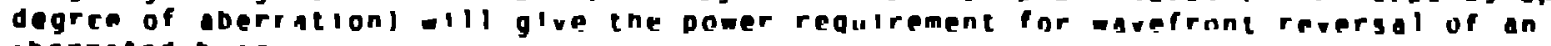
uberigea buen. 


\section{St1mulated Backward Brillouin Scattering (SBBS)}

Stimulated backward Brlllouin scattering has been extensively investigated in tine past although malily not in conjunction with prase conjugation. The first demonstration of the effect dates back to 1964 [9]. The use of SBBS for phase ccnjugation has been first demonstrated by zel'dovich in 1972 [10] and consequently in the visible and near ir parts of the spectrum by several groups [ 1 and references there]. In all cases highly coherent pulsed lasers (Ruby. Nd:YAG) have been used.

In this paragraph we elicidate the physical principles behind SBBS in a simpla qualitative way which, however, provides an understanding of icquirements and limitations for the wavefront reversal of aberrated beams. Rather complex quant tat lve mathematical analys is can be found in the literature. Figures $2 a-2 c$ outline the relevant physical effects.

Flgure 2 a shows the Brillouin reflectlon of a coherent optical beam frow an acoustic ultrasonic wave. The acoustlc wave of wavelength $\lambda_{s}$, frequency $\omega_{s}$ and velocity $v_{s}\left(v_{s}-\omega_{s} \lambda_{s} / 2 \pi\right)$ forms a moving grating. An optical beam of wevelength $\lambda_{0}\left(2 \lambda_{s}\right)$ incident on the acrustic wave at the Bragg angle $\theta_{B}\left(2 \lambda_{s} \cos \theta_{B}\right.$ mas $\lambda_{0}$ - integer) wlll experience a intror reflection through posttive interference and a Dopuler frequency shift. The frequency shift will be $w_{s}$.

Angular Resolution. The acceptance angle of the grating (angles fulf flling 3ragg condtions for postt ve interference) will be $6_{B} \pm \delta 0$, where $\delta \theta \sim 1 / / N$, N being the number of Brugg planes. The angular resolution uf the grating will thus be $21 / \mathrm{K}$ (notice: for agiven grating and alven tncldent beam, there wlll be 3 ingle well-defined reflection angle. For given incident beam and a given reflection angle, there will be many N-Bragg-planes ratings fulf llling the Bragg condieton. The angular separation between these gratings will be up to so $21 / / N$ ).

Figure 20 deplcts the way ty which optical radiation can interact with transparent matter to produce an intensity grating. Since electrical dipoles inte. act with the gradient of an electrlc fleld, and ootical intenstey gradient (DI) will induce a matertal density gradient. An analysis of this effect (elertro: iriction) shows that the effective mechanical pressures involved are closely equal co the radiation pressure of a "photon gas" I/C, c - light velocity.

Figure $2 c$ elucidates the amplification process of a weak optical beam (frequency w) precisely rounterpropagating a strong beam (freauency $\omega_{0}, \omega-\omega_{0}=\omega_{5}<<\omega_{0}$ ). v10 Brillo"in scattering in a traisparellt material. The two counterpropagating beams interfere to produce d moving intensity grating of plane separation $\lambda_{0} / 2$. " We equals the sound frequency $f c^{-}$an acciustic wavelength $\lambda_{s}=\lambda_{0} / 2$, the system $w 1$ ! f resonate to pruduce a moving density eirating (acoustic wave). The strong beam wlll be backmard reflected (Bragg riflecticn) from the acoustic wave and frequency shifted just to beat with the incident leam and to enhance the acoustlc wave. The net result of thls positive feedback is the amplifflcatlor. of the weak beam and tha disappearance "f tha strong beam. The galn at each point is proportional to the Incident neamis intensity I. To observe a net gain, thi amplification process has to compete with losses due to viscosity lacoustic wave decayl and to optical absorption.

SBB:- A coherent optlical beam $c$ f high enough intenslity can be backward-reflected (phase conjugded) and frequency slifted whlle impinging on o iassive transparent materlal. This is achieved via Brlllouln scattering. Referring again to rig. ?c, weak optlcal beams at frequency ws-ws are always present as eero point fluctuntions. Tre backward amplification process inrough interference wich the intense bear at frequency wo. described above. call be applifil to the noisy beams. For gn Input beam of intensity I above some threshold intenslty leli (In IIqu'ds. I th $2 \mathrm{GH} / \mathrm{cm}^{2}$. deoending upon the viscosity and optical ahsorption in the passive material). Enclsy beom counterpropagat ing the Input beam wil experience e net ampliflicition. thus causing the appearance of a st'mulated burkund scatterej benm. In this process, a stimulated acoustle kave is also belng produced. The number $N$ nf it lmulated Bragg planes responsible for an efficlent ( 2 loox backward reflection ol the innut beam will determine the angular inaccuracy

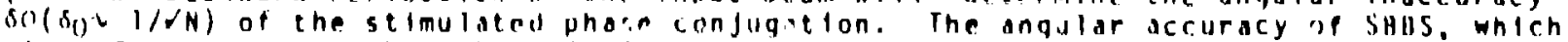
stems from the fact that the stimulated acoustic waves and the scatterina process start from nolse is in contrast to ine anqular accuracy uf phase confugate reflection in four-wave mixing where the diffection gratings are belng produced irom well preallgned beams. For probe beams brighter than iero noint fluctuations. I.e., high enough gignal nolse ritio.l 


\section{SBBS of a Focused Coherent Beam}

iBBS can be achleved by focusing a coheirent beam of intensity I into a transparent matertal. See Fig. 3a. By using a lens of small enougt $f_{\text {Nolf }}$ No $\equiv / 0$. focal length/ diameter). the threshold tntensity for SBBS can be attained at the focal region which is of diameter $\lambda_{0} F_{\mathrm{No}}$. He list and explain several requirements for achieving good quality - pliase conjugate reflection of a focused beam:

$$
\text { a. } f_{N_{0}} \leq \sqrt{I / I_{t h} \lambda_{0}^{2}} \text { (For threshold intenstiy at the focal reglon.) }
$$

b. The angular divergence of the stimulated backward reflected beam at the focal regton may be $0 / f$ for diffraction-limited recollimation by the lens of diameter $D$. This requires the utilization of $N=(f / D)^{2}$ stimulated Bragg planes for the stinulated backward reflection, and consequently the entire focal reglon. Since the reflectivity of each Bragg plane at threshoid is a well-defined quantity determined by the materlals properties, the focal region should not be longer than $2 \lambda_{0} / R$; we thus also require

\section{$f_{\text {No }} \times \sqrt{T / R}$.}

For each transparent material we thus have a maximum fo. Independent of intensity. above which no diffraction limited SBBS is possible.

C. The coherence
$\ell_{c}>$ focal length region:

c. The coherence length $\ell_{c}$ required frum the laser teing used in SBBS is

$$
l_{c}>\frac{\lambda_{0}}{r} \cdot \frac{1}{\Gamma_{\operatorname{th}^{\lambda_{0}}}}
$$

Image Retention in SBBS

To analyze the laser power requirements for high quality image retention of a pliase conjugatid beam via SBBS, one decomposes the input beam into a set of plan? waves (FIg. Jo). Each plane wave silmulates lts olil ultrasontc-reflecting sound wave. To wthin a first order of magnitude the power requirement from a single plane wave (a:tainment of threshold ot the focal region) multiplied by the number of plane waves (which depends on the spatial frequency content of the modulated input hedm) wili give the power requirement for tmage retention. However, it should be reallzad that for a given image, not all tourter (plane waves) components are of equal intansicy. For sone frequency components threshold may not he attatned simultaneously with others, thus preventing high quality Image retention of the SBBS beam. We thus have a imitatinn for image rutention in SBBS of focused beam. which toes not holo li, four-wava mixting.

Thls limitation can partially be circurvented by using tapered waveyulde conflgurations [10-13], as orlglnally suggested by zel'dovich and andiyzed by Helluarth.

\section{Experimental Demonstration of SBBS wth an Ultiaviolet Exclmar Laser}

The first demunstrations of phase conjugate reflection with axclmer idser beams were carrled out with KrF lasers af $2486 A$. Successiul Injecilon-locking of the KrF laser [4.6] provided in $21 \mathrm{~cm}$ congrence length (2 50 GHz bandwldth) whlch was sufflclent for both four-wave mixing exparlments $(6,7)$ and sBbs (the frec runginglaser bandwidth was $210 \mathrm{~A})$. The nonlinenr medlum (liquids) whleh were used absorbed the uitravlolri radiation yutte strongly (2 $25 \mathrm{k} / \mathrm{cm})$. Fur four-wave mixina experiments, this absorption was necessary for the production of thermal gratillgs. However, for sBbs the absurption semed to deterlorate the reflocted beam's quality. Although reflectlulties higher than

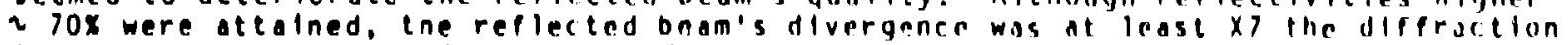
Ilmil and the process did not reproduce liself from shot to shot.

In an effort to galn better understanding of the nhase conjugation properties of

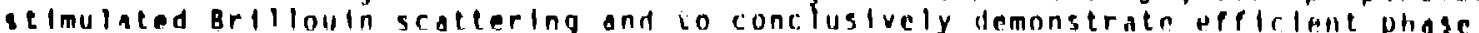
conjugation in the ultravlolet. We sought to match liquids whlch are nonabsorbing with an ultraviolet laser of long coherence longth. In particular, we have successfully demonstratad tlie injection locking of an xef discharqe laser using as ifo injection source the colncidental output of an $A R^{++}$laser transteton at 351 A [5]. This lasor. when used with transarent liquids with large Brillouln yalns (and knnwn acoustic deray elmes substantialiy sliorter thou thr 30-ns laser pulse) provided an lacal situation to Investigate the BSB: process and demonstratod effictent jtraviolet phase conjugation. 


\section{Experimental Setup for SBBS}

The experimental setup is depleted 16 FIy. 4 . A pulsed low power (2 $1 \mathrm{H}$ ) Ar-lon laser ( 2 1-GHz bandwlath) operating on the Ar-III 3511 A transition is used to infection lock an unstable resonator Xef laser. The free-running Xef laser had mutiline bandwidth of $2, i(500 \mathrm{GHz})$. Whereas the locked $x_{e F}$ osctilator, described In Ref. [ 8$]$, emits $260 x$ of tis energy in the $16 H z$ bandwidth (coherence length 250 Ca) and $i 40 x$ of its energy in other unlocked transitions which are not avaliable for locking because they originate from different upper states. The 2 50-mJ output ( 2 30-ns pulse duration) is in a square cross-section beam $18-m m$ wide with a hole (6-mm diameter) in the center. The locked rajiation is polarized. whereas the remaining unlocked output is unpolarized. A detafled description of the injection-locked laser can be found in Ref. [5]. See paper paper $K 6$ in these pioceedings.

Agaln referring to Fig. 4, the 2 1-MW locked Xef laser beam is passed through a varlable aperture mask (A) and a varlable ND $f 1$ lter (ND) and is focused into a cell containing a liquid. The focal length of the focusing lens ( $L$ ) is varied between $15 \mathrm{~cm}$ and $100 \mathrm{~cm}$. A peilicle beamsplitter (OS, Bx reflectivity) directs the (phase-conjugated) beam toward a Fabry-perot etalon with the spacing set to $0.5 \mathrm{~cm}$. A corner cube retroret lector (RR) directs the idser beam toward the same etalon. A photographic film at the focal plane of a $100-\mathrm{cm}$ lens (LC) can record simultaneously the spectra of the laser and the phase-conjugated beams. The $30 \mathrm{GHz}$ free spectral range of the etalon and 1 ts finesse ( 220 ) provide a nigh enough spectral resolution ( $21.5 \mathrm{GHz}$ ) to observe the expected Brliloutn frequency shift $26 \mathrm{GHz}$ for Hexane).

A 0.1 -A-resoiution ultraviolet giating spectrometer was used to determine whether or not the unlocked Xef output was also phase conjugated. The time histortes of the laser and phase conjugated pulses were then analyzed using a fast photodiode, and the divergence and spatial qualits of the beams were photographlcally recrided at a large distance $(25 \mathrm{~m})$ from the llquid cell. The polarization of the phase conjugated beam was also weasured.

\section{Experimental Results}

We have trled several liquids as Brllloutn scatterers, the best results belng obtalned with hriane, iscpropyl alcohol and benzene. The phase-conjugated reflectivities with these llaulas were $240 x$ of the total laser power. which corresponis to $270 x$ of the fraction of laser power locked to the Ar-lon laser transition. These reflectivities were odtancd with focal lengths of $15-50 \mathrm{~cm}$ (f-number oetween 7.5 and 25 ). Threshold conditions for BSBS were obtalned with a $100-\mathrm{cm}$ focal length lens and a 4 -mm aperture in front of the laser. For these condttions ( $f(2,250)$ the intenstey at the focal region was $<86 \mathrm{H} / \mathrm{cm}^{2}$ and the $10 \mathrm{cal}$ depth $\left(\lambda \mathrm{fho}_{0}\right)$ was $21.8 \mathrm{~cm}$.

ADove threshold, the phase conjugated benms were found to be of diffraction-li:iced divergence. Flgure $5 e$ shows the laser energy oistrloution on the photographic plate located 2. $5 \mathrm{~m}$ from the laser when a mask of several $4 \mathrm{~mm}$ holes ivas p'iced it the output of the laser. Figure 50 shows the mergy distribution of the phase-conjugated beam at the same distance. Both the laser and reflected beams aredifraction ifmited. The spacings between the spots in Figs. 5a and 5b are different since the laser output beam was slightly divergent, and consequently the rhase conjugated beam was slight ly conversent. providing additional confirmation of the conjugation process.

Flgures 6. 7, and 8 give some inslaht into the physical process of ultravialet phase-conjigation with an xef laser. I quare 6 shows the grating spectrogram of the laser beam (lower spectrum) ond the phase conjugated beam (upper spectrum). We see that the reflected beam contains unly the laser's power spectrum that le within the 2 GHz bandwidth locked to the 3511 A ar-ion line. indicating that the moving gratino formed In the BSBS process orts as a narrowband filter. A simflar filtration effect has recontly been seen with degenerate four-wave $m|x| n g[1<]$. Thus. Fig. 6 stringly suggests that the BSBS has been produced ma nly by the narrow baldwidth, polarized. locked xef transltion. An additional conftrmation of this flltering process was obtained hy finding that the phase conjugaled beam was completely polarlzed the polarization state belng that of the iocking Ar-ion laser). The unlocked transitions were unpolarlzed.

In Fig. I we present the high resolution (1.5 SHz) Fabry-purot interferograms of the laser beam and the phase confugated beam. Flqure ?a shows the locked laser transtitlon (1.). In Fly. ib there ire three lines (L, H,$\theta_{2}$ ). Which correspond to the laser cranstiton $(i)$. thr phase conjugated beam (Bi) Prequency shifted by 26 GHz (first stuke besm) and a second-stokes phase-conjugated beam (B?). Wo belleve that this second-stokes beam arises in the following manner: the first. Stokes beam returns to the ulistable resonator and enters with correct alignment (since it is a phase-corjugate 
reflection). It travelz "backwards" in the cavity unt ll il reaches the paraxial region Whereupon (alded by self-diffraction) it starts to work it. Way back out. It then reemerges slightly amplifled (since its Brillouln-shifted wavelength is still within the gain-bandwidth of the XeF medium) and subsequently undergoes BSBS in the liquld cell. ccounting for the doubly-shifted light. Similar multiple-shift effects were observed oy Hon [1?] In Brillouin-scattering pulse-conpression studies at $1.06 \mathrm{um}$, but were first see in the early days of BSBS studies.

Figure 7c shows only a first-stokes shift. It was obtalned when a $10 x$ transmlssion No fliter was placed at the jutjut of the XeF laser. The inftial output of the Xef laser was thus slightly above threshold for BSAS but the first-stokes reflection experlenced the attenuation two mare times (bothentering and leaving the unstable resonator) and so was below threshold upon its second arrival at the liquid cell.

Oscilloscope traces of the laser and phase-conjugated pulses are presented $\ln F / g$. $B$. Figure 8 a shows the normal XeF laser pulse, whereas $r i g$. Uo shows the laser output when the first-Stokes beam is allowed to reenter the cavlty. The dip shortly after the peak is due to gain depletion caused by the first-stokes beam which at that time is traveling backwards in the cavity. Figura BC shows a typlcal phase-conjugated BSBS pulse. We belleve that the earlier portion is the first-Stokes beam and that the latter portion is the doubiy-shifted beam. The early termination of the first-stokes reflection corresponds to the dip in the laser output see in Fig. $8 b$.

When the Brillouin rell was moved -o a greater distance ( $25 \mathrm{~m}$ ) from the laser, the first-5tckes beam returned to the laser after the gain was terminated. In this case the dip in Fig. $8 b$ disappeared, the duration of the flrst-stokes reflection increased (by $250 x$ of the or (ginal width), and no second stokes was seen.

Additlorally, the effect of bulk absorption In the Brillouln liquid was examined by dissolving various absorbers in the hexane or isopropanol. Consideratie degradation of the spatial quality of the phase-conjugated beam occurred by absorptlons $>10 x / \mathrm{cm}$ at 3511 . The observec bedin looked similar to what we have prevtously observed in our studies of KrF BSBS in lifulds which were al soroing at $2485 \mathrm{~A}$. The mechanisms for thls degradation are presently being studied.

\section{Conclusions}

He have used I MH injection-locked unstable resonator xef laser to produce efficient phase-conjugction of an uitraviolet (A-35) A) ieam via stimulated Brillouln scattering. Approximately $70 x$ of the ! GHz bandwidth XeF laser energy (locked to a reference Ar-ton trastilon) was phase conjugaled by focusing the laser bem into Hexane or isopropyl alcohol. Approximately $40 x$ of the Xef laser output energy was not avallable for locking ano was not phase conjugated. The stimulaied acoustlc grating in the liquld thus acted as a narrow-bandwidth filter. Both the laser beam and the l-GHz bandwidth phaseconjugated bean were diffrection limited.

The first-stokas retroreflected beam was oble to reenter the xef unstable resonator (to which it was automatically mode-matched by the hase-conjugation process) a:d to emerge slightly amplifled, thus enabling the ganeration of a second-stokes phaseconjugated buam. Thls effect cemonstrates the posslotilty of using a stimulated acoustirg gratling as a pase-conjugating mirror for the cavity of a second excimer laser. enabling study of the propertles of excimer laser operation when one of the mirrors is a phase cuilugator [15]. Since the brillouin mirror produces a frequency shift upon each reflection.

Finally. the introduction of an absorber into the Brlllouin llquid caused a considerabie decerforation of the reflected ueam's spatlal quality. This problem and the possioflity of partialiy circumventing limitation to image retention in 5 Bbs by using tapered wavegulde conflgurations are presently belng investlgated. It is still ar open question wheli,er or not four-wave mixing conflguration or an 58 as conflguration is practically odvantageous for phase conjugation, ihlgh-pnwer ultraviolet excimer laser beam. 


\section{References}

[1] A. Yariv, IEEE J. Quant. Electron. QE-14, 650 (1978).

[2] B. J. Feidman. R. A. Fisher. S. L. Shaptro, Opt. Lett. 6.84 (1981).

I. J. Btglo. M. Slatkine, Opt. Lett., Vol.6, No. 7 (1981).

M. Slatkine. 1. J. Bigto: Conference on Lasers and Electro-Optics CLE0 81. post-deadline paper. Hashington (1981).

[5] I. J. Biglo. M. Slatkine, to be publtshed in Opt. Lett.. (Jan. 1982).

M. Siatkine. I. J. Blg10, Opt. Soc. of Am. Annuai Meeting. Orianto, (oct. 1981).

[6] R. G. Caro. M. C. Gower, Conference on Lasers and Electro-0ptics. CLEO 'Bl.

[7] post-deadline paper ThSil. Washington (198i).

[7] I. J. Biglo, J. J. Feldman, R. A. Fisher and M. Slatkine, Conference on Lasers afid Electro-Optics, CLEO 'Bl, post-deadline paper ThS3, Washington (1981).

[8] M. Slatkine. I. J. Bigio, B. J. Faldman, R. A. Fisher, to be published in Opt. Lett.

(9) R. Y. Chtao, C. H. Town. B. P. Stotcheff Phys. Rev. Lett. 12. 592 (1964).

[10] B. Y. Zeldovich et al.. sov. Phys. JETP is, 109 (1972).

(11) D. T. Hon, J. Opt. Soc. Am. 70,635 (1980).

12\} D. Y. Hon, Opt. Let t. 5,516 (ig80).

[13\} R. H. Heliwarth in "nptical Phase Conjugation, "edited by R. A. Fisher. Academic Press. Inc.. N. Y.. to be published.

[14] J. Nilsen, N. S. Giuck, are A. Yuriv, Upt. Lett. 6, 380 (1981).

[15\} J. AuYeung et ai., IEEE J. Quant. Electron. QE-15,':180 (1979;.

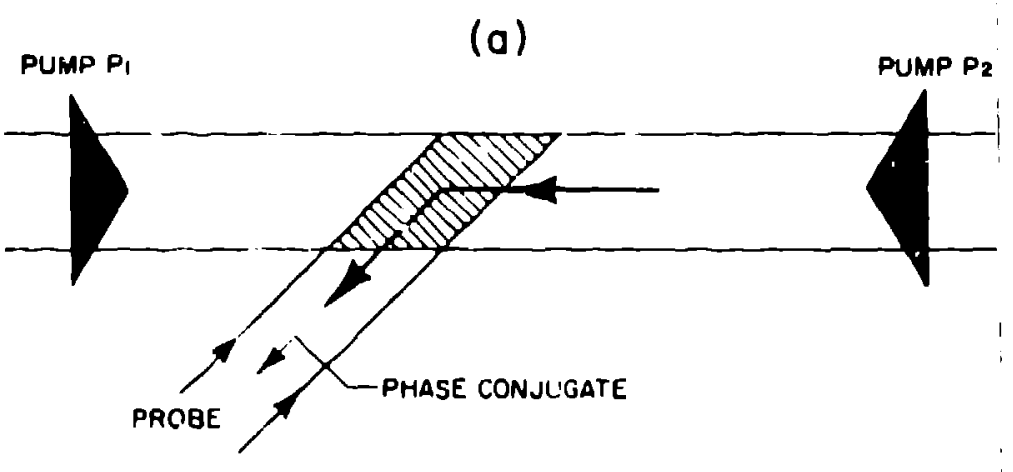

Figure 1 .

a) Schematics of phase conjugation of a probe plane wave via degenerate four-wave $m 1 \times \operatorname{lng}$.

(b)

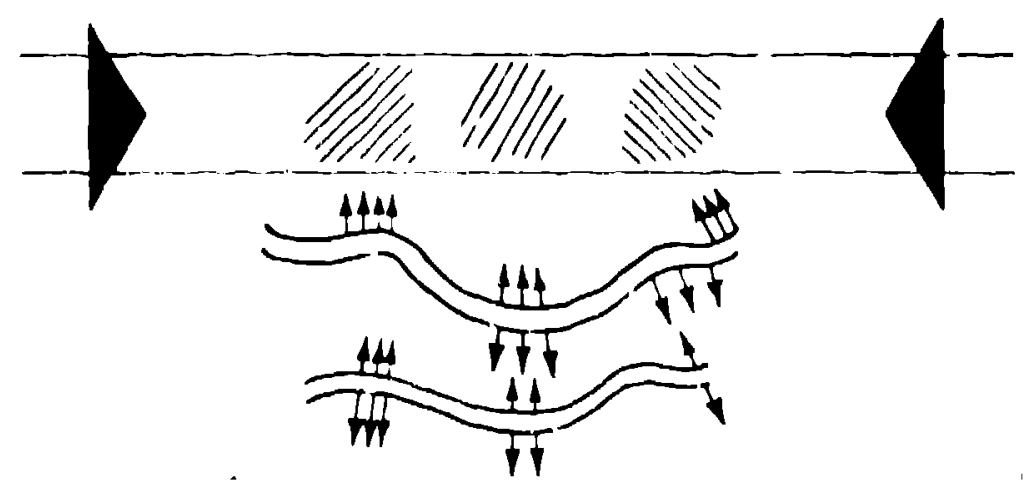




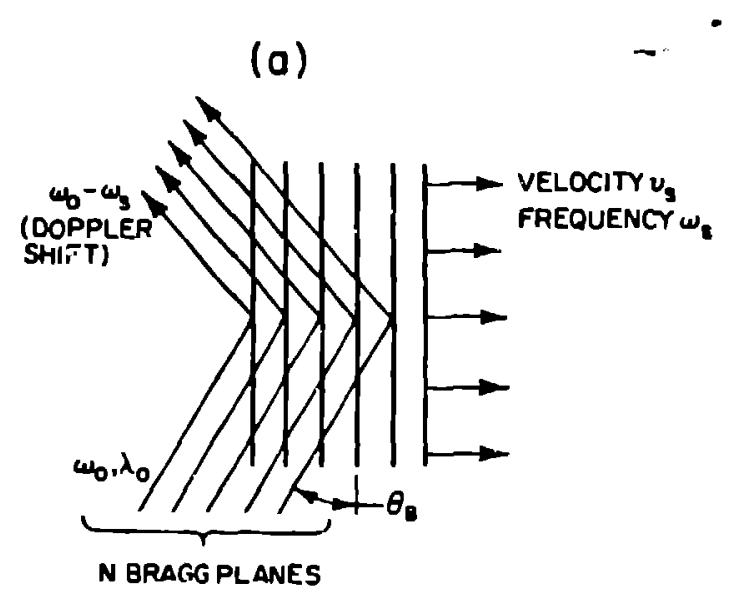

Figure 2 .

a) The Brillouin effect - Bragg reflection from an ultrasonic wave. The Bragg acceptance angle is determined to within an accuracy of $\delta \theta=1 / V N$.

(b)

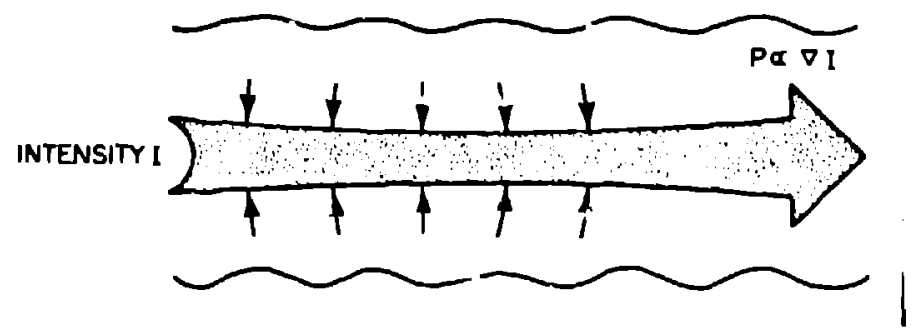

D) Electrostrictive radiation pressure: A radiation intensity gradient force on a transparent matertal. An intensity grating will induce a material denstiy grating via electrostriction.

(c)

c) The amplification of a weak beam (frequency $\omega_{0}-w^{2}$ ) counterpropagating a strung beam (frequency $\omega_{0}$ ) via Brilloutn scattering.

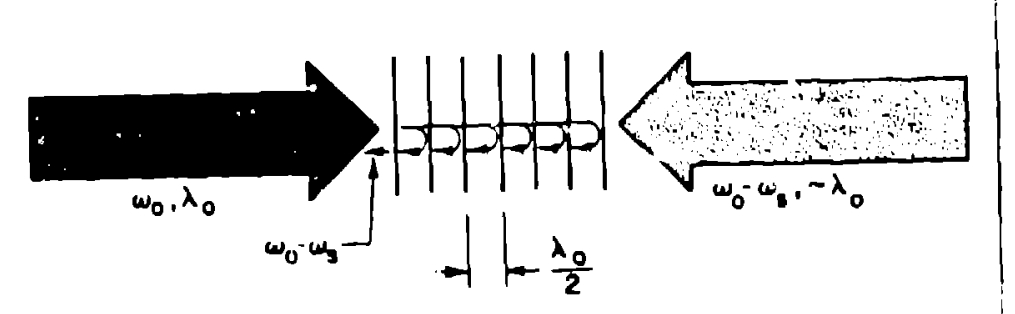

(o)

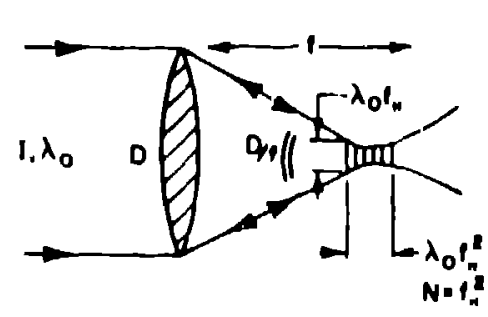

(b)

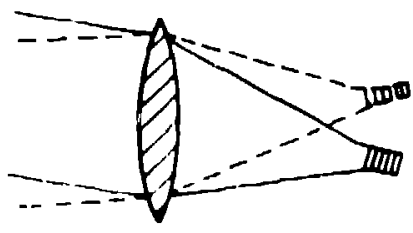

Figure 3. A) SBBS of acused plane wave. A mall enough so and dong encugh coherence length are required for : yh-quality SBBS.

b) Image retention in SaBs can be analyzed by decomposing the spatially modulated input beam into a set of plane waves. 

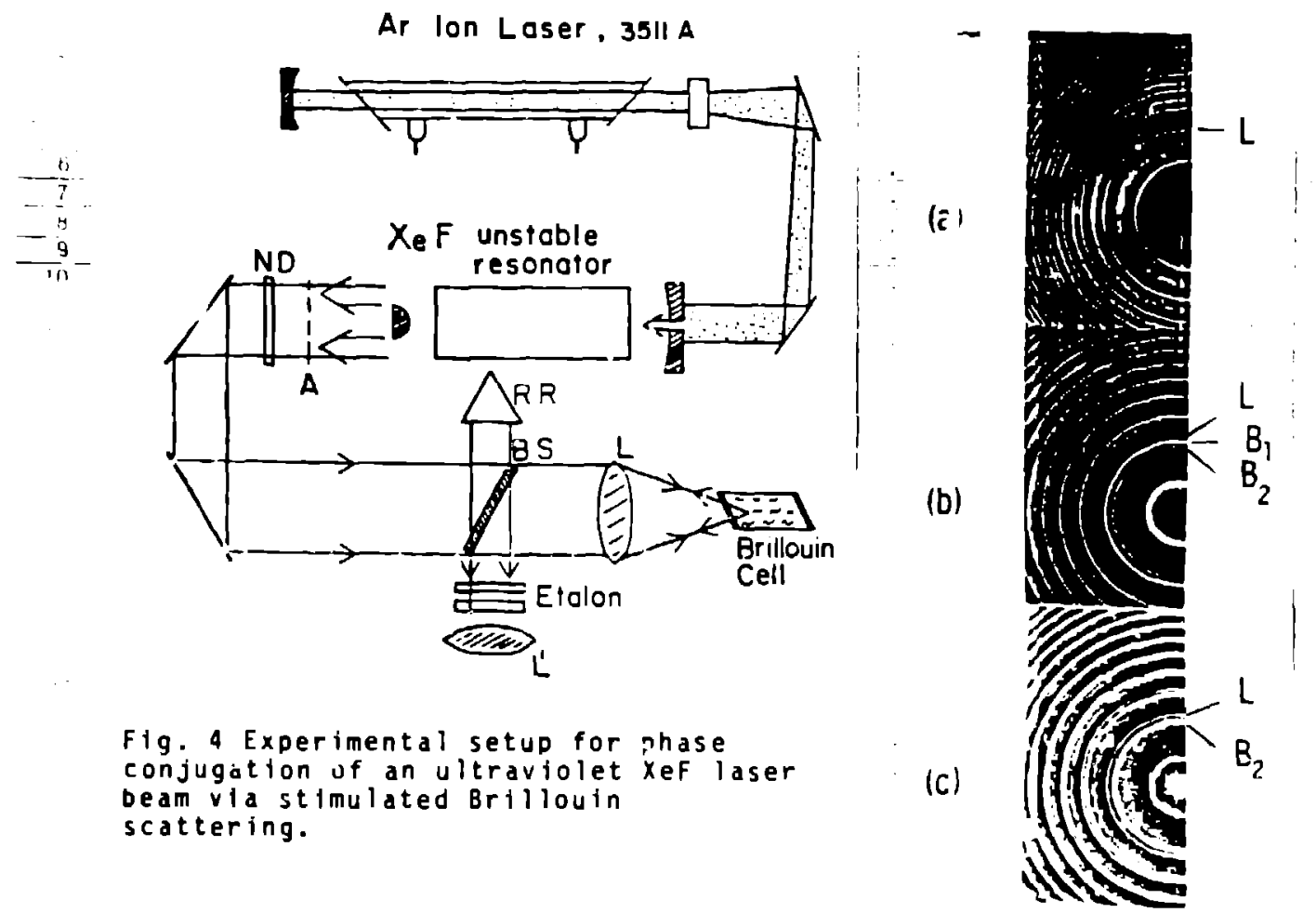

Fig. 7 . High
resolution GHz) Fabry-Perot interferograms of the laser and phase conjugated beams: a) liser beari $L$; b) laser. Le and first and second-stokes
phase-conjugated phase-conjugated beams, B B B : c) an NDi filter has been placeo at the output of the

laser. Only

first-stokes is vistole.

Fig. 4 Experimental setup for phase conjugation of an uitraviolet xef laser beam via stimulated Brillouin scattering.

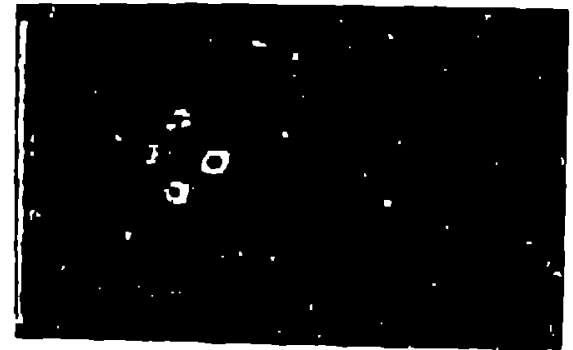

(a)

(b)

Fig. 5. Intenstey distribution of laser light transmitted through a mask with four 4-mm-dlameter holes placed at the output of the laser: a) laser beam (silghtly diverient): j) phase-conjugated beam (sightly divergent).

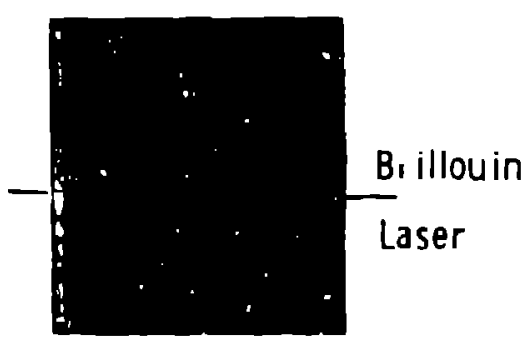

Fig. 6. Grating spectrogram 10.11 resolution) of the injection-locked XeF laser (lower spectrum) and the phase conjugated reflection (upper spectrum).

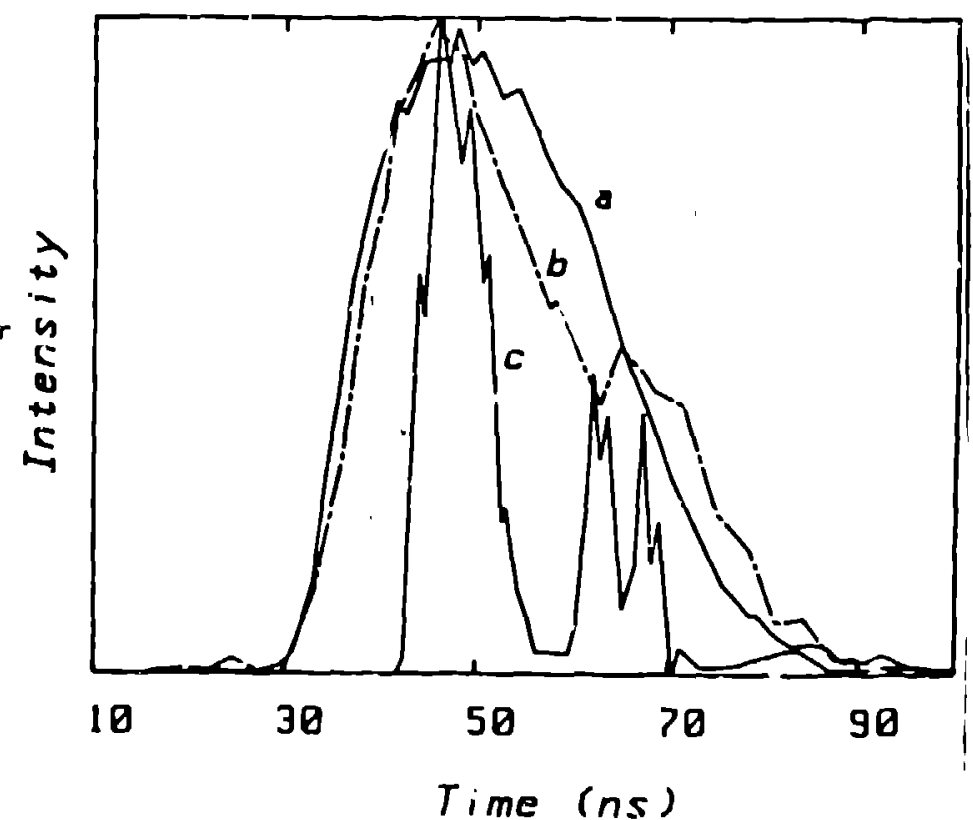

Fig. B. Time historles of laser and phase-conjugated pulses: a) laser pulse with no Brilloutll cell; b) laser pulse showing gain depletion due to backward traveling Briliouin stgnals; c) firstStakes and seconu-Stokes reflections. 